\title{
Effect of Src tyrosine kinase on a rat model of asthma
}

\author{
MIN WU*, JINGPING YANG ${ }^{*}$, TAO LIU, PENGFEI XUAN, BAOYING BU, XIYUAN XU and RINA WU \\ Department of Respiratory and Critical Medicine, The Third Affiliated Hospital of \\ Inner Mongolia Medical University, Baotou, Inner Mongolia Autonomous Region 014010, P.R. China
}

Received September 22, 2020; Accepted October 1, 2021

DOI: $10.3892 /$ etm.2021.11095

\begin{abstract}
Src tyrosine kinase is a protein encoded by the Src gene. The present study aimed to determine the role of Src protein kinase in asthma using small interfering RNA (siRNA) technology. Several Src siRNAs were designed and the most effective siRNA pair was selected. A rat model of asthma was established using ovalbumin, and the rats were treated with Src siRNA, empty vector or phosphate-buffered saline (PBS). A non-asthmatic control group was also established. The rats were clinically observed and Src mRNA and protein levels were measured by reverse transcription-quantitative PCR and western blot analysis, respectively. Pathological observation of the lung tissue, counting of white blood cells (WBCs) and eosinophils (EOSs) and analysis of the concentrations of IL-5, IL-33 and IFN- $\gamma$ in the bronchoalveolar lavage fluid were performed. The expression levels of Src mRNA in the control, PBS, empty vector and siRNA groups were $110 \pm 30.7 \times 10^{3}$, $253 \pm 55.4 \times 10^{3}, 254 \pm 41.3 \times 10^{3}$ and $180 \pm 50.9 \times 10^{3}$, respectively. Histochemical analysis of the lung tissue of rats in the siRNA group exhibited a relatively complete lung structure and little damage to the alveolar cavity. Src protein expression and IL-5, IL-33 levels, WBC and EOS levels were positively correlated with Src mRNA expression, while the IFN- $\gamma$ concentration was negatively correlated with Src mRNA expression. These results indicate that Src knockdown inhibits the release of tracheal inflammatory factors and significantly alleviates asthma in rats. In conclusion, the present study utilized a gene transfer technique to interfere with the expression of Src in rats, which decreased the levels of IL-5, IL-33, WBCs and EOSs and increased the level of IFN- $\gamma$; these changes effectively ameliorated the condition of the trachea in asthmatic rats.
\end{abstract}

Correspondence to: Dr Xiyuan Xu or Dr Rina Wu, Department of Respiratory and Critical Medicine, The Third Affiliated Hospital of Inner Mongolia Medical University, 20 Shaoxian Road, Kundulun, Baotou, Inner Mongolia Autonomous Region 014010, P.R. China E-mail: yangzhisci@126.com

E-mail: 852495257@qq.com

*Contributed equally

Keywords: asthma, small interfering RNA, gene transfer techniques, protein-tyrosine kinases, reverse transcription-quantitative PCR

\section{Introduction}

Asthma is a chronic lung disease that is often diagnosed in childhood. It affects 339 million individuals worldwide and $\sim 1,000$ individuals die each day from asthma (1). Asthma involves chronic tracheal inflammation, which is mediated $\mathrm{T}$ helper 2 cells and exhibits symptoms including reversible expiratory airflow limitation, wheezing, shortness of breath, chest tightness and cough. Hypertrophy and hyperplasia of the tracheal smooth muscle caused by chronic tracheal inflammation thicken the tracheal wall and goblet cells, leading to increased mucus production and narrowing of the trachea $(2,3)$. Although researchers have extensively investigated this topic, the mechanism has not been fully elucidated (4). Currently, numerous commercially available drugs demonstrate good inhibitory efficacy against asthma, but the incidence and mortality remain high. Therefore, it is urgently necessary to clarify the mechanism of asthma and design new therapeutics.

RNA interference (RNAi), also known as post-transcriptional gene silencing, involves the transfer of double-stranded RNA into cells to silence or inhibit the expression of target genes and serves an important role in gene regulation $(5,6)$. The silencing of target genes with RNAi has been used for the inhibition of genes associated with cancer (7).

To date, 90 types of tyrosine kinase enzymes have been identified in humans $(8,9)$. Tyrosine kinase Src, a member of the Src kinase family, belongs to the non-receptor tyrosine kinase family. Previous studies have demonstrated that Src kinase regulates cell metabolism, and its signalling pathway participates in apoptosis, cell proliferation and development $(10,11)$. Furthermore, Src has been revealed to participate in the development of lung cancer and HIV infection (12).

The present study utilized a gene transfer technique to transfer small interfering RNA (siRNA) into rats with asthma and thereby interfere with the expression of the Src gene. Through the analysis of the lung tissues and bronchoalveolar lavage fluid (BALF) of the rats in different groups, the effect of Src protein kinase on asthma was elucidated.

\section{Materials and methods}

Materials. Concentrated goat serum and Cy3-labeled Goat Anti-Rabbit IgG (cat. no. BA1034) were purchased from Wuhan Boster Biological Technology Co., Ltd.; 
Entranster $^{\mathrm{TM}}$-in vivo (cat. no. 18668-11-1) was purchased from Engreen Biosystem, Ltd.; Lipofectamine ${ }^{\circledR} 2000$ was purchased from Invitrogen (Thermo Fisher Scientific, Inc.); DNA marker was purchased from TransGen Biotech Co., Ltd.; RNAiso Plus, PrimeScript RT Reagent kit and SYBR Premix Ex Taq $^{\text {TM }}$ II (Tli RNaseH Plus) were purchased from Takara Bio, Inc.; IL-5 (cat. no. E-EL-R0558c; Elabscience Biotechnology, Inc.), IL-33 (cat. no. CSB-E14077r; Cusabio Technology LLC) and IFN- $\gamma$ (cat. no. CSB-E04579r; Cusabio Technology LLC) ELISA kits, and CD90 (cat. no. E-AB-70323) and CD45 (cat. no. E-AB-16319) antibodies were purchased from Elabscience Biotechnology, Inc.

Animals. A total of 32 healthy male Sprague Dawley (SD) rats, aged 4 weeks and weighing 200-280 g, were provided by the Animal Research Centre of Inner Mongolia Medical University. The rats were acclimated for 1 week prior to the experiments. The SD rats were provided with continuous standard rodent chow and water and were housed in a rodent facility at $24 \pm 2^{\circ} \mathrm{C}$ and $45 \sim 65 \%$ relative humidity environment with a 12 -h light/dark cycle. All procedures involving animals and their care were conducted in accordance with the Guide for the Care and Use of Laboratory Animals (8th Edition), which was established by the National Academy of Sciences and published by the National Institutes of Health.

Cultivation and identification of rat bone marrow mesenchymal stem cells. A healthy male rat (aged 4 weeks and weighing $70 \mathrm{~g}$ ) was humanely sacrificed by intraperitoneal anesthetization with $1 \mathrm{~g} / \mathrm{kg}$ urethane followed by cervical dislocation and then immersed in $75 \%$ ethanol for $15 \mathrm{~min}$. Bone marrow was extracted from bilateral femurs and rinsed with a-Minimum Essential Medium (a-MEM; cat. no. SH30265; Hyclone; Cytiva) containing $10 \%$ foetal calf serum (cat. no. SH30070; Hyclone; Cytiva) and $1 \%$ penicillin-streptomycin (cat. no. SV30010; Hyclone; Cytiva). The resulting single cell suspension was centrifuged at $850 \times \mathrm{g}$ and $25^{\circ} \mathrm{C}$ for $7 \mathrm{~min}$. The supernatant was removed, and the cells were resuspended with a-MEM containing $10 \%$ foetal calf serum and $1 \%$ penicillin-streptomycin. The suspended cells were cultured and passaged at $37^{\circ} \mathrm{C}$ with $5 \% \mathrm{CO}_{2}$. All processes were performed in a sterile environment.

After rinsing with phosphate-buffered saline (PBS), the cells were fixed with $4 \%$ paraformaldehyde for $15 \mathrm{~min}$ at room temperature and rinsed with PBS three times. Then, $0.5 \%$ Triton $\mathrm{X}-100$ was dropped onto the slides, and the slides were maintained at $20^{\circ} \mathrm{C}$ for $20 \mathrm{~min}$. After rinsing and removing the residual liquids, $5 \%$ goat serum (Beijing Solarbio Science \& Technology Co., Ltd.) was dropped onto the slides and the slides were set aside to block for $30 \mathrm{~min}$ at $37^{\circ} \mathrm{C}$. Following this, when the blocking reagent was absorbed, diluted (1:100) CD90 and CD45 antibodies were dropped onto each slide and the slides were incubated at $4{ }^{\circ} \mathrm{C}$ overnight. The slides were then washed and diluted (1:100) Cy3-labeled Goat Anti-Rabbit IgG was dropped onto the slides, which were subsequently incubated at $37^{\circ} \mathrm{C}$ for $1 \mathrm{~h}$. After staining with DAPI at room temperature for $15 \mathrm{~min}$, the slides were observed under a fluorescence microscope (magnification, $\mathrm{x} 20$ ).

Table I. Sequences of rat Src siRNAs (11).

Name $\quad$ Sequence $\left(5^{\prime}-3^{\prime}\right)$

Scrambled-siRNA-F

Scrambled-siRNA-R

Src-rno-1208-F

Src-rno-1208-R

Src-rno-708-F

Src-rno-708-R

Src-rno-995-F

Src-rno-995-R

AGAGCCGAUUCCUUAACAATT
UUGUUAAGGAAGCGGCUCUTT
CAGAGCGGCUACUUCUCAATT
UUGAGAAGUAGCCGCUCUGTT
GCGGCUGCAGAUUGUCAAUTT
AUUGACAAUCUGCAGCCGCTT
GCCUAAAUGUGAAACACUATT
UAGUGUUUCACAUUUAGGCTT

The scrambled sequences served as the control. siRNA, small interfering RNA; F, forward; R, reverse.

siRNA transfection of rat bone marrow mesenchymal stem cells. Based on the nucleotide sequence of Src in the National Centre for Biotechnology Information (NCBI) GenBank database (13), sequences of siRNA targeting Src were designed and synthesized by Sangon Biotech Co., Ltd., as presented in Table I. A stock solution $(40 \mu \mathrm{M})$ was prepared by adding $125 \mu \mathrm{l}$ diethyl pyrocarbonate (DEPC) into siRNA. After mixing, the solution was divided into $6-\mu \mathrm{l} /$ tube portions and preserved at $-20^{\circ} \mathrm{C}$. Transfection was conducted as follows: Solution A was prepared by dissolving $0.25 \mu \mathrm{l}$ siRNA in $50 \mu \mathrm{l}$ Opti-MEM. Solution B was prepared by dissolving $0.25 \mu$ l Lipofectamine 2000 in $50 \mu \mathrm{l} \mathrm{Opti-MEM}$, and leaving to stand for $5 \mathrm{~min}$ at $20^{\circ} \mathrm{C}$. The two solutions were mixed in a $1: 1$ ratio to form solution $\mathrm{C}$ and maintained at room temperature for $20 \mathrm{~min}$. When the density of rat bone marrow mesenchymal cells in a 96-well microplate reached $>50 \%$, the medium was removed and replaced with $800 \mu \mathrm{l} /$ well a-MEM. Solution $\mathrm{C}$ was then added. Following incubation for $6 \mathrm{~h}$ at $37^{\circ} \mathrm{C}$ in a cell incubator, the medium was replaced with a-MEM containing $10 \%$ foetal calf serum and $1 \%$ penicillin-streptomycin and the cells were incubated for a further $24 \mathrm{~h}$ at $37^{\circ} \mathrm{C}$. The cells were collected, and the total RNA was extracted from the cells and examined by reverse transcription-quantitative PCR (RT-qPCR).

Extraction and quantitative analysis of $m R N A$ by $R T-q P C R$. All Eppendorf (EP) tubes and pipette tips used in this procedure were sterile and RNase-free. Firstly, cells were rinsed twice with PBS, $200 \mu 1$ RNAiso Plus was added and the cells were maintained at $20^{\circ} \mathrm{C}$ for $2 \mathrm{~min}$. After mixing the solution, $40 \mu \mathrm{l}$ chloroform was added, the sample was kept at $4^{\circ} \mathrm{C}$ for $3 \mathrm{~min}$ and then centrifuged at $12,000 \mathrm{x} \mathrm{g}$ for $15 \mathrm{~min}$ at $4^{\circ} \mathrm{C}$. The supernatant was transferred into a new EP tube, mixed with $200 \mu \mathrm{l}$ isopropyl alcohol and allowed to stand at $20^{\circ} \mathrm{C}$ for $10 \mathrm{~min}$. The mixture was then centrifuged at $12,000 \mathrm{x} \mathrm{g}$ for $10 \mathrm{~min}$ at $4^{\circ} \mathrm{C}$. Following removal of the supernatant, the residual layer was washed with $200 \mu 175 \%$ ethanol and centrifuged at 7,500 $\mathrm{xg}$ and $4^{\circ} \mathrm{C}$ for $5 \mathrm{~min}$. The supernatant was removed and the residual alcohol was volatilized at $20^{\circ} \mathrm{C}$. The RNA residue was dissolved in $30 \mu \mathrm{l}$ DEPC and preserved at $-80^{\circ} \mathrm{C}$.

The total RNA $(1.0 \mu \mathrm{g})$ was placed in an RNase-free tube with $2 \mu \mathrm{l} 5 \mathrm{X}$ gDNA eraser buffer and $1 \mu \mathrm{l}$ gDNA eraser (cat. 
no. RR047A; Takara Bio, Inc.), and RNase free distilled water $\left(\mathrm{dH}_{2} \mathrm{O}\right)$ was added to a total volume of $10 \mu \mathrm{l}$. The mixture was maintained at $42^{\circ} \mathrm{C}$ for 2 min and the product was preserved at $4^{\circ} \mathrm{C}$. Then, $1 \mu \mathrm{l}$ PrimeScript RT Enzyme mix, $1 \mu$ l RT Primer mix and $4 \mu 1$ 5X PrimeScript Buffer from the PrimeScript RT Reagent kit and $4 \mu \mathrm{l}$ RNase-free $\mathrm{dH}_{2} \mathrm{O}$ were added to provide a mixture with a total volume of $20 \mu 1$. This mixture was incubated at $37^{\circ} \mathrm{C}$ for $15 \mathrm{~min}$ followed by $85^{\circ} \mathrm{C}$ for $5 \mathrm{sec}$. The solution of cDNA product was preserved at $4^{\circ} \mathrm{C}$.

Based on the NCBIGenBank database sequence of the rat Src gene, primers for Src were designed using the Primer-BLAST tool (https://blast.ncbi.nlm.nih.gov/Blast.cgi?PAGE_ TYPE=BlastSearch\&BLAST_SPEC=OGP_10116__10621\& LINK_LOC=blasthome) and synthesized by Sangon Biotech Co., Ltd. The primer sequences were as follows: Src forward, 5'-CTTCCTCGTGAGGGAGAGTG-3' and reverse, 5'-TGG GACACACGGTAGTGAGA-3'. GAPDH served as the internal control gene with primer sequences as follows: Forward, 5'-TGCTGAGTATGTCGTGGAG-3' and reverse, 5'-GTCTTC TGAGTGGCAGTGAT-3'.

For qPCR, $10 \mu 1$ SYBR Premix Ex Taq II (Tli RNaseH Plus) (2X), $4 \mu \mathrm{l}$ diluted cDNA (200 ng/ $\mu \mathrm{l}), 0.8 \mu \mathrm{l}$ forward primer $(10 \mu \mathrm{M}), 0.8 \mu \mathrm{l}$ reverse primer $(10 \mu \mathrm{M})$ and $4.4 \mu \mathrm{l}$ double $\mathrm{dH}_{2} \mathrm{O}$ were mixed to provide $20 \mu \mathrm{l}$ reaction mixture. The thermocycling protocol for qPCR is presented in Table SI.

Quantitative analysis was based on the $2^{-\Delta \Delta \mathrm{Cq}}$ method (14). The average relative content $(\%)=$ relative content of unknown sample/relative content of control sample $=2^{\text {-average } \Delta \mathrm{Cq}}$, where $\Delta \mathrm{Cq}_{\text {unknown sample }}=\mathrm{Cq}_{\text {unknown sample }}-\mathrm{Cq}_{\text {control sample }}$.

Construction of an animal model of asthma. A total of 32 SD rats were randomly divided into four groups named the control, model (PBS), empty vector and siRNA groups. To establish the asthma model, a 100- $\mu 1$ mixture comprising $50 \mu \mathrm{g}$ ovalbumin (OVA; cat. no. A5503; Sigma-Aldrich; Merck KGaA) and $2 \mathrm{mg}$ aluminium hydroxide (cat. no. 239186; Sigma-Aldrich; Merck $\mathrm{KGaA}$ ) in saline was administered intraperitoneally to rats in the PBS, empty vector and siRNA groups on days 2 , 11 and 22. The rats in the control group were injected with same volume of saline at the same time points. In addition, the rats in the PBS, empty vector and siRNA groups were exposed to 5\% OVA inhalation for $20 \mathrm{~min}$ each day from day 22 for 5 days. The control group inhaled atomized saline at the same time points.

Transfection assay. To evaluate the role of Src in the rat model of asthma, $250 \mu \mathrm{l} \mathrm{Src} \mathrm{siRNA}(0.5 \mu \mathrm{g} / \mu \mathrm{l})$ and $250 \mu \mathrm{l}$ transfection compound (Entranster ${ }^{\mathrm{TM}}$-in vivo) were diluted with $250 \mu \mathrm{l}$ PBS, mixed and allowed to stand for $20 \mathrm{~min}$ on day 1, prior to administration to the siRNA group via intravenous injection (100 $\mu$ l per rat). At the same time point, the rats in the PBS and empty vector groups were injected with the same volume of PBS and transfection compound, respectively. On day 2, the $100-\mu 1$ mixture comprising $50 \mu \mathrm{g}$ OVA and $2 \mathrm{mg}$ aluminium hydroxide was injected intraperitoneally into the rats in the PBS, empty vector and siRNA groups. Subsequently, the siRNA and transfection compound were injected intravenously into rats in the siRNA group on days 8,15 and 22, while rats in the PBS and empty vector group were treated with the same volume of PBS and transfection compound, respectively. On day 22, $2 \mathrm{~h}$ after injection, the rats in the PBS, empty vector and siRNA groups were transferred to a closed container, where they breathed 5\% atomized OVA for $20 \mathrm{~min}$. This OVA inhalation process was performed once a day for 5 days. The control group inhaled the same quantity of atomized saline instead. Following the final atomization, the rats in the four groups were humanely sacrificed by anesthetization with $1 \mathrm{~g} / \mathrm{kg}$ urethane and cervical dislocation, and their BALF as well as lung and bronchus tissues were collected for follow-up examination.

Histochemistry. Lung and bronchus tissues were fixed in $4 \%$ paraformaldehyde at room temperature for $24 \mathrm{~h}$, embedded in paraffin, sliced into $4 \mu \mathrm{m}$-thick sections, stained with haematoxylin for $5 \mathrm{~min}$ and eosin for $3 \mathrm{~min}$ at room temperature, dehydrated and fixed. Slices were examined at high magnification (x100) using an optical microscope.

Determination of Src mRNA in tissues. Tissue samples (50 mg) were ground quickly in a mortar with liquid nitrogen and then transferred to an EP tube. Following the addition of $1 \mathrm{ml} \mathrm{TRIzol}$ (Invitrogen; Thermo Fisher Scientific, Inc.) and mixing, the tube was left to stand at $20^{\circ} \mathrm{C}$ for $5 \mathrm{~min}$. Then, chloroform $(200 \mu \mathrm{l})$ was added, the mixture was shaken intensely for $15 \mathrm{sec}$ and set aside for $3 \mathrm{~min}$ at $2^{\circ} \mathrm{C}$. After that, the mixture was centrifuged at $13,800 \mathrm{x} g$ for $15 \mathrm{~min}$ at $4^{\circ} \mathrm{C}$. The RNA-containing supernatant was transferred to a new EP tube, treated with $500 \mu \mathrm{l}$ isopropanol for $10 \mathrm{~min}$ at room temperature and then centrifuged at $13,800 \mathrm{x} \mathrm{g}$ for $10 \mathrm{~min}$ at $4^{\circ} \mathrm{C}$. Following removal of the supernatant, $1 \mathrm{ml} 75 \%$ alcohol was added, the mixture was centrifuged at 5,400 $\mathrm{x} \mathrm{g}$ for $5 \mathrm{~min}$ at $4^{\circ} \mathrm{C}$ and the supernatant was removed. The precipitate was dried at $20^{\circ} \mathrm{C}$, then dissolved with $25-200 \mu \mathrm{l}$ DEPC $\mathrm{H}_{2} \mathrm{O}$ for further use. The total RNA was extracted by this procedure for examination of the mRNA levels by RT-qPCR as described above.

Examination of protein tyrosine kinase Src. The rat tissue was ground, put into a tube with lysis buffer (cat. no. P0013; Beyotime Institute of Biotechnology) and protease inhibitor, and then centrifuged at $13,800 \mathrm{x} \mathrm{g}$ and $4^{\circ} \mathrm{C}$ for $10 \mathrm{~min}$. The supernatant was collected and preserved at $-20^{\circ} \mathrm{C}$. A $10-\mu 1$ sample was taken and diluted 10-fold with PBS buffer. The diluted solution was added to three wells (20 $\mu \mathrm{l} /$ well) and $200 \mu \mathrm{l} \mathrm{G}-250$ (Coomassie Brilliant Blue) was added to each well and mixed. After $2 \mathrm{~min}$, a biophotometer was used to determine the absorbance value at $595 \mathrm{~nm}$. BSA $(1 \mathrm{mg} / \mathrm{ml}$; cat. no. V900933; Sigma-Aldrich; Merck KGaA) was added the cells of a 96-well plate at volumes of $0,1,2,4,6,8$ and $10 \mu \mathrm{l}$, followed by distilled water to a total volume of $20 \mu \mathrm{l}$. These BSA standards were stained using G-250 using the aforementioned method. A standard curve was then created for estimating the protein concentration of the samples. After that, the samples were examined by western blotting and Scr expression was analysed by the measurement of its optical density at the corresponding molecular weight. In brief, for each sample, $30 \mu \mathrm{g}$ protein was loaded in each lane, separated by $10 \%$ SDS-PAGE, and then transferred to a PVDF membrane (cat. no. ISEQ00010; MilliporeSigma). Following blocking with $5 \%$ skimmed milk at room temperature for $30 \mathrm{~min}$, the membranes were incubated with a primary antibody against 


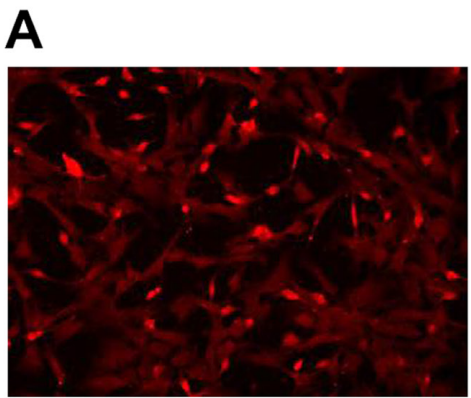

CD90 (x200)

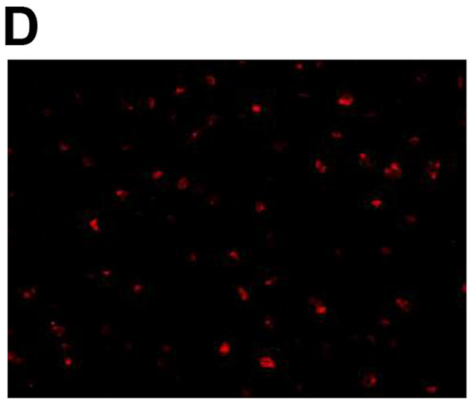

CD45 (x200)

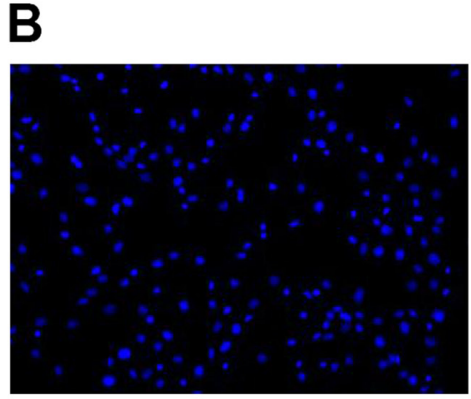

DAPI $(x 200)$

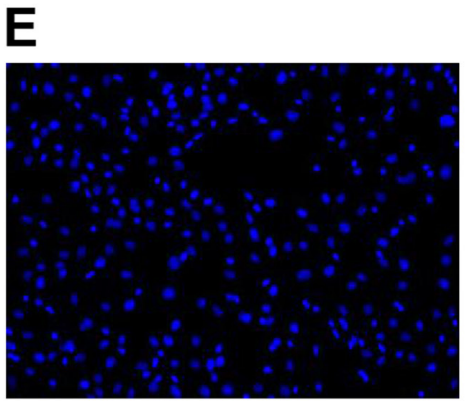

DAPI (x200)

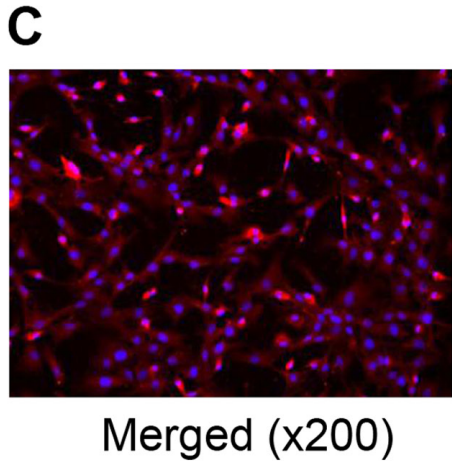

$\mathbf{F}$

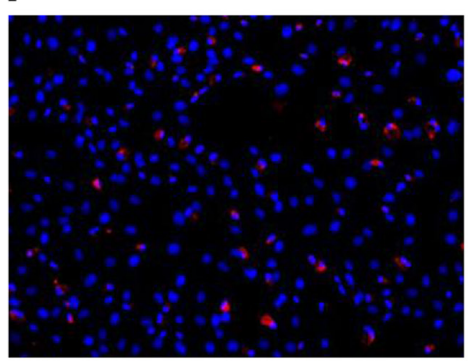

Merged (x200)

Figure 1. Identification of rat bone marrow mesenchymal stem cells in vitro. CD45 and CD90 were labelled with Cy3 (red) and the cells were stained with DAPI (blue). The results were observed by fluorescence microscopy. (A) CD90 labelled with Cy3 fluorescence; (B) DAPI staining; (C) merged CD90 and DAPI staining. The positive rate of CD90 was $>90 \%$. (D) CD45 labelled with Cy3; (E) DAPI staining; (F) merged CD45 and DAPI staining. The positive rate of CD45 was $<5 \%$.

SRC (cat. no. ab231081, 1:1,000; Abcam) at $4^{\circ} \mathrm{C}$ overnight or a primary antibody against GAPDH (cat. no. 200306-7E4, 1:1,000; Chengdu Zhengneng Biotechnology Co., Ltd.) at room temperature for $2 \mathrm{~h}$. The membrane was washed with TBS with Tween-20 (TBST; 10 mM Tris-Cl, pH 7.5, $100 \mathrm{mM} \mathrm{NaCl}$ and 1\% Tween-20) five times for $8 \mathrm{~min}$ and incubated with a HRP-conjugated goat anti-mouse antibody (cat. no. A0216; 1:5,000; Beyotime Institute of Biotechnology) for $1 \mathrm{~h}$ at room temperature. After washing with TBST five times for $8 \mathrm{~min}$, the blots were exposed by using ECL Chemiluminescent Substrate (cat. no. 180-5001; Tanon Science and Technology Co., Ltd.) and signals were recorded under the 5200chemiluminescent visualized system (Tanon Science and Technology Co., Ltd.). Band density was semi-quantified using ImageJ software V1.8.0 (National Institutes of Health).

Analysis of BALF. Samples of BALF were centrifuged at $1,650 \mathrm{x} \mathrm{g}$ for $15 \mathrm{~min}$ at $4^{\circ} \mathrm{C}$. The supernatant was separated from the precipitate and each component was preserved separately. The precipitate was re-suspended with PBS and cell smears were prepared. After drying at room temperature, cells were fixed with methanol for $15 \mathrm{~min}$ at room temperature and then stained with Wright-Giemsa staining solution for $20 \mathrm{~min}$ at room temperature. The number of white blood cells (WBCs), eosinophils (EOSs) and total cells were counted under a microscope (H550S; Nikon Corporation). The proportion of these two cells in the total cells was calculated from five fields of view. The supernatant was employed to determine the concentration of IL-5, IL-33 and IFN- $\gamma$ in the BALF using ELISA kits.
Data analysis. SPSS 25.0 (IBM Corp.) was used to perform the statistical analysis. Results are presented as the mean \pm SD from three independent experiments. Application of Levene's test confirmed the homogeneity of variance. The statistical significance of differences among groups was detected using one-way ANOVA followed by Tukey's post hoc tests. In the siRNA group, the correlations of Src mRNA expression with Src protein expression, the number of EOSs and the expression of inflammatory factors were statistically analysed using Pearson's correlation test. $\mathrm{P}<0.05$ was considered to indicate a statistically significant difference.

\section{Results}

Identification of rat bone marrow mesenchymal stem cells. Cells isolated from the rat bone marrow and cultured in vitro were small in volume, with a shuttle-like morphology and a low cytoplasmic ratio. When examined using immunofluorescence staining, the cultured cells exhibited positive expression of CD90 and weak expression of CD45. As shown in Fig. 1A-F, after counting the number of positive and total cells, it was found that the CD90 positive rate was $>90 \%$ and the CD45 positive rate was $<5 \%$.

Expression of Src mRNA in vitro. As shown in Fig. 2A, relative to GAPDH, the expression of Src mRNA in the negative control group was $0.1295 \times 10^{3}$, that in the Src-rno-1208 group was $0.0309 \times 10^{3}$, that in the Src-rno-708 group was $0.0198 \times 10^{3}$, and that in the Src-rno-995 group was $0.0179 \times 10^{3}$, which was the lowest $(\mathrm{P}<0.05)$. This indicates that among the siRNAs 
A

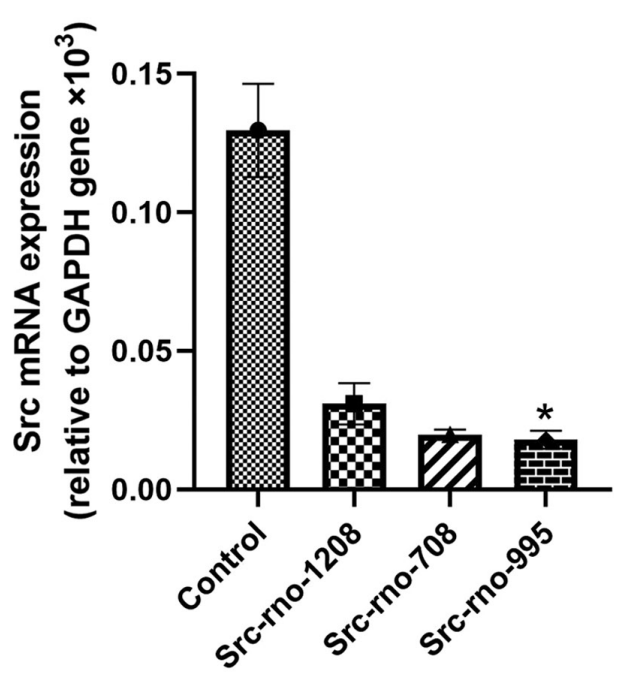

C

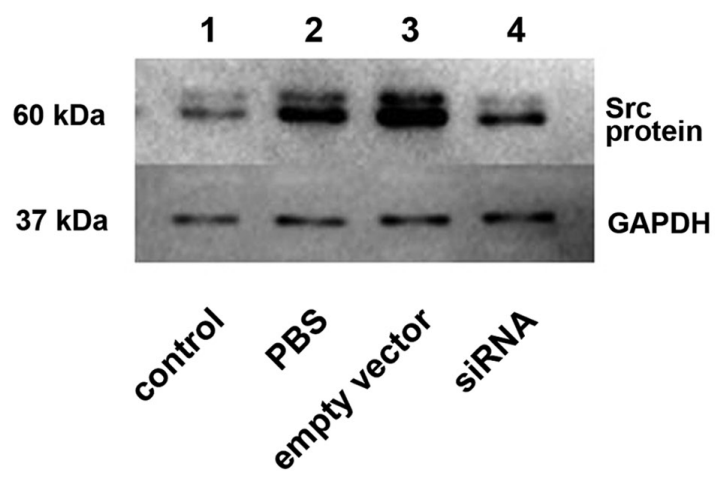

B

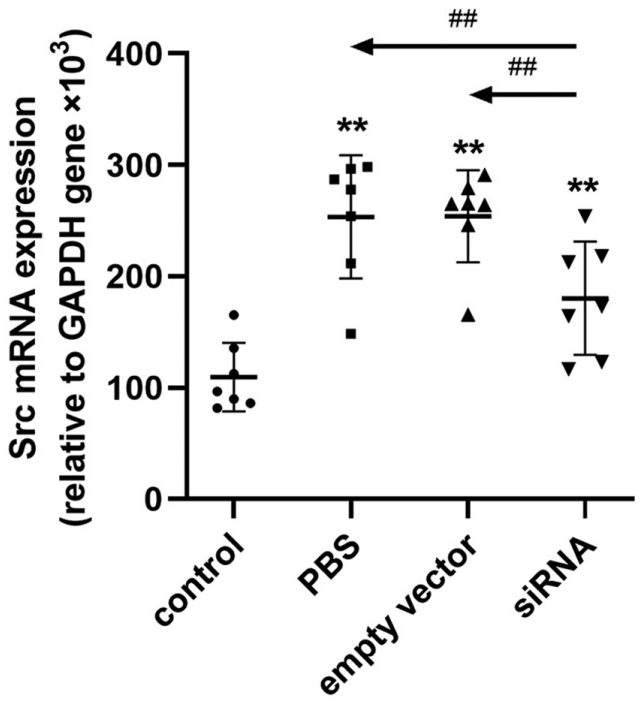

D

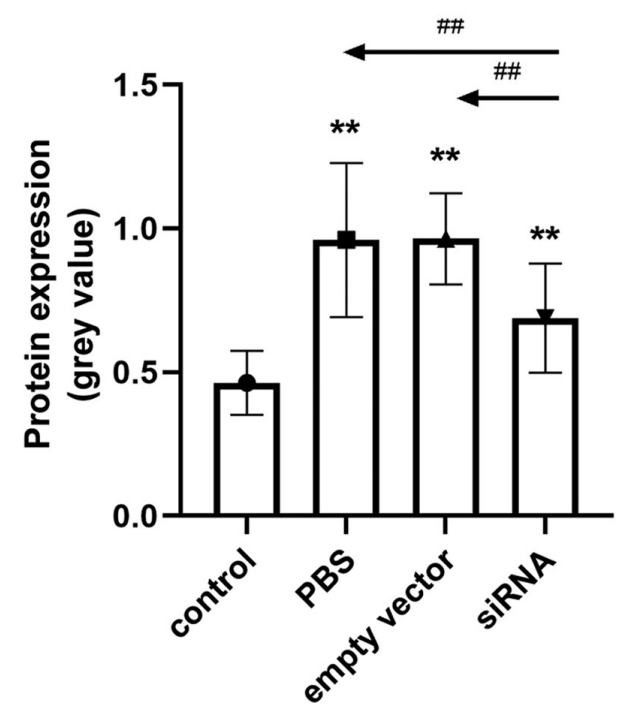

Figure 2. Expression of Src mRNA in vitro and in vivo. (A) Src mRNA expression in rat bone marrow mesenchymal stem cells following interference by various Src siRNAs in vitro, determined via RT-qPCR. (B) Src mRNA expression in different groups of rats in vivo, determined via RT-qPCR. (C) Representative western blots of Src protein in each group of rats, with GAPDH as the loading control. (D) Average grey values of Src protein in vivo. ${ }^{*} \mathrm{P}<0.05$ and ${ }^{* *} \mathrm{P}<0.01$ vs. the control group; ${ }^{\#} \mathrm{P}<0.01$ vs. the siRNA group. siRNA, small interfering RNA; RT-qPCR, reverse transcription-quantitative PCR.

tested, Src-rno-995 had superior efficacy in interfering with Src mRNA. Therefore, Src-rno-995 was selected for use in subsequent experiments.

Clinical observation and histopathology in vivo. Rats in the control group exhibited normal behaviour, glossy fur and no symptoms of asthma or cough. In the PBS and empty vector groups, the rats had less glossy fur, poorer appetites and lower activity levels than the controls. In addition, following the final OVA atomization challenge, the rats exhibited anxiety, deep breathing, nose grabbing and purpura. The rats in the siRNA group displayed glossy fur and obviously improved appetites and activity levels when compared with the rats in the PBS and empty vector groups (data not shown).

The H\&E staining results were as follows: In the control group, the bronchial structure and alveolar septa were normal, the alveolar cavities were clear and no inflammatory cell infiltration was observed in the lung mucous membrane (Fig. 3A). As shown in Fig. 3B and $\mathrm{C}$, in the PBS and empty vector groups, the epithelial structure of the trachea was incomplete. Mucous gland hyperplasia was evident and the secretion of mucus by goblet cells was increased; mucous plug development was visible in the small bronchi. The alveolar septa narrowed, the alveolar cavities were fused and tissue oedema was observed. Inflammatory cell infiltration was visible at the tracheal wall and surrounding area, where the inflammatory cells were mainly lymphocytes and EOSs. In the siRNA group, the bronchial structure was relatively normal and the epithelial structure was almost complete (Fig. 3D). Destruction of the alveolar cavities was mild. Furthermore, inflammatory cell infiltration and mucous secretion were mild in comparison with those in the PBS and empty vector groups.

Expression of Src mRNA in lung tissue. As shown in Fig. 2B, the Src mRNA levels in the control, PBS, empty vector and siRNA groups were $110 \pm 30.7 \times 10^{3}, 253 \pm 55.4 \times 10^{3}, 254 \pm 41.3 \times 10^{3}$ and $180 \pm 50.9 \times 10^{3}$, respectively. The expression levels of Src mRNA in the PBS and empty vector groups were significantly 
A

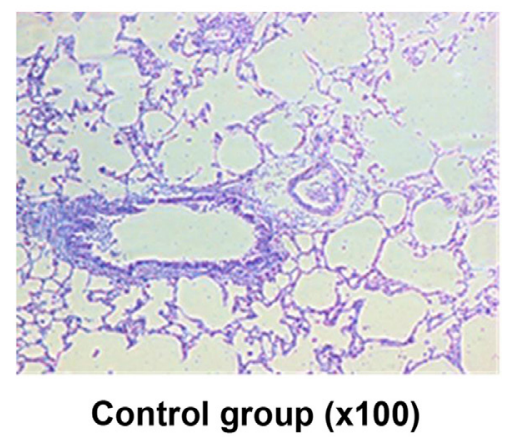

C

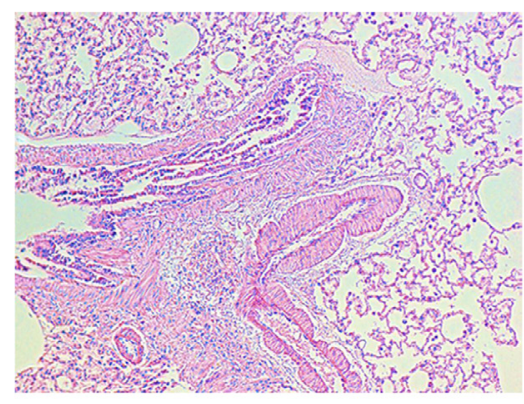

Empty vector group (x100)
B

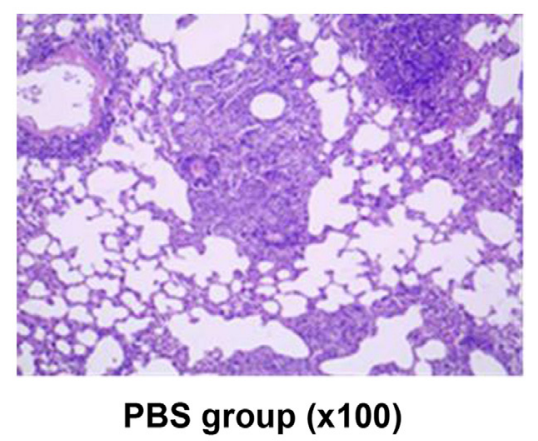

D

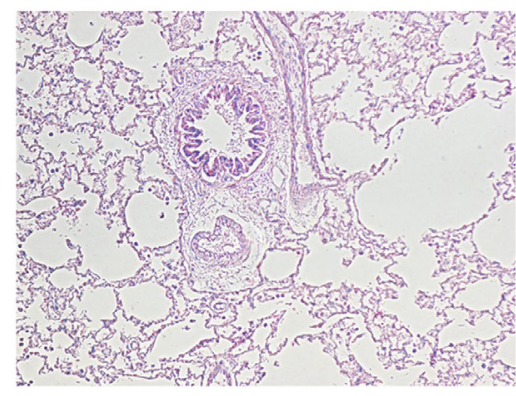

SiRNA group (x100)

Figure 3. Pathological observation of lung tissue of rats from four different groups using haematoxylin and eosin staining. Lung tissue of the (A) control group, (B) PBS group, (C) empty vector group and (D) siRNA group. siRNA, small interfering RNA.

higher compared with that in the control group $(\mathrm{P}<0.01)$, and the expression of Src mRNA in the siRNA group was significantly higher compared with that in the control group $(\mathrm{P}<0.01)$, but significantly lower compared with those in the PBS and empty vector groups $(\mathrm{P}<0.01)$. No difference in Src mRNA expression was detected between the PBS and empty vector groups.

Src protein expression in the lung tissue. Fig. $2 \mathrm{C}$ shows representative western blotting results for the lung tissue and Fig. 2D presents the greyscale values of the Src protein compared with those of GAPDH. The relative greyscale values for the Src protein in the control, PBS, empty vector and siRNA groups were $0.463 \pm 0.111,0.960 \pm 0.268,0.964 \pm 0.159$ and $0.688 \pm 0.190$, respectively. The Src protein levels in the PBS and empty vector groups were significantly higher compared with that in the control group $(\mathrm{P}<0.01)$. The Src protein level in the siRNA group was significantly lower compared with those in the PBS and empty vector groups $(\mathrm{P}<0.01)$ and higher than that in the control group $(\mathrm{P}<0.01)$. No difference in the Src protein level was identified between the PBS and empty vector groups.

Quantification of WBCs and EOSs in BALF. As shown in Fig. 4A and B, in the BALF of the control, PBS, empty vector and siRNA groups, the numbers of WBCs were $10.5 \pm 2.95 \times 10^{6}$, $86.7 \pm 18.9 \times 10^{6}, 86.3 \pm 14.0 \times 10^{6}$ and $33.8 \pm 14.8 \times 10^{6}$ cells $/ \mathrm{ml}$, respectively, and the numbers of EOSs were $0.986 \pm 0.277 \times 10^{6}$, $14.2 \pm 3.10 \times 10^{6}, 14.2 \pm 2.31 \times 10^{6}$ and $4.34 \pm 1.78 \times 10^{6} \mathrm{cells} / \mathrm{ml}$, respectively. The numbers of EOSs and WBCs in the PBS and empty vector groups were significantly higher compared with those in the control group $(\mathrm{P}<0.01)$; the numbers of these cells in the siRNA group were also significantly higher than those in the control group $(\mathrm{P}<0.01)$ but significantly lower than those in the PBS and empty vector groups $(\mathrm{P}<0.01)$. No difference was detected between the PBS and the empty vector groups.

Expression of IL-5, IL-33 and IFN- $\gamma$ in BALF. The concentrations of IL-5, IL-33 and IFN- $\gamma$ in the BALF samples from the control, PBS group, empty vector and siRNA groups are shown in Fig. 4C-E. The concentrations of IL-5 and IL-33 in the PBS and empty vector groups were significantly higher compared with those in the control group $(\mathrm{P}<0.01)$; the concentrations of IL-5 and IL-33 in the siRNA group were also significantly higher than those in the control group $(\mathrm{P}<0.01)$ but significantly lower than those in the PBS and empty vector groups $(\mathrm{P}<0.01)$. The concentrations of IFN $-\gamma$ in the PBS and empty vector groups were significantly lower than those in the control group $(\mathrm{P}<0.01)$. The IFN- $\gamma$ level in the siRNA group was also significantly lower than that in the control group $(\mathrm{P}<0.01)$ but significantly elevated compared with IFN- $\gamma$ levels in the PBS and empty vector groups $(\mathrm{P}<0.01)$. No difference was observed between the PBS and empty vector groups.

Correlation analysis of Src siRNA. As shown in Fig. 5A and B, in the siRNA group, the EOS, IL-5 and IL-33 levels exhibited a positive correlation with $\mathrm{Src}$ mRNA expression $\left(\mathrm{r}^{2}=0.824\right.$, 0.724 and 0.722 , respectively; $\mathrm{P}=0.0047,0.0183$ and 0.0155 , respectively). IFN- $\gamma$ levels were negatively correlated with the Src mRNA level $\left(\mathrm{r}^{2}=0.798, \mathrm{P}=0.0067\right.$; Fig. $\left.5 C\right)$. In addition, the Src protein level was positively correlated with the Src mRNA level $\left(r^{2}=0.8466, P=0.0033\right.$; Fig. 5D). 

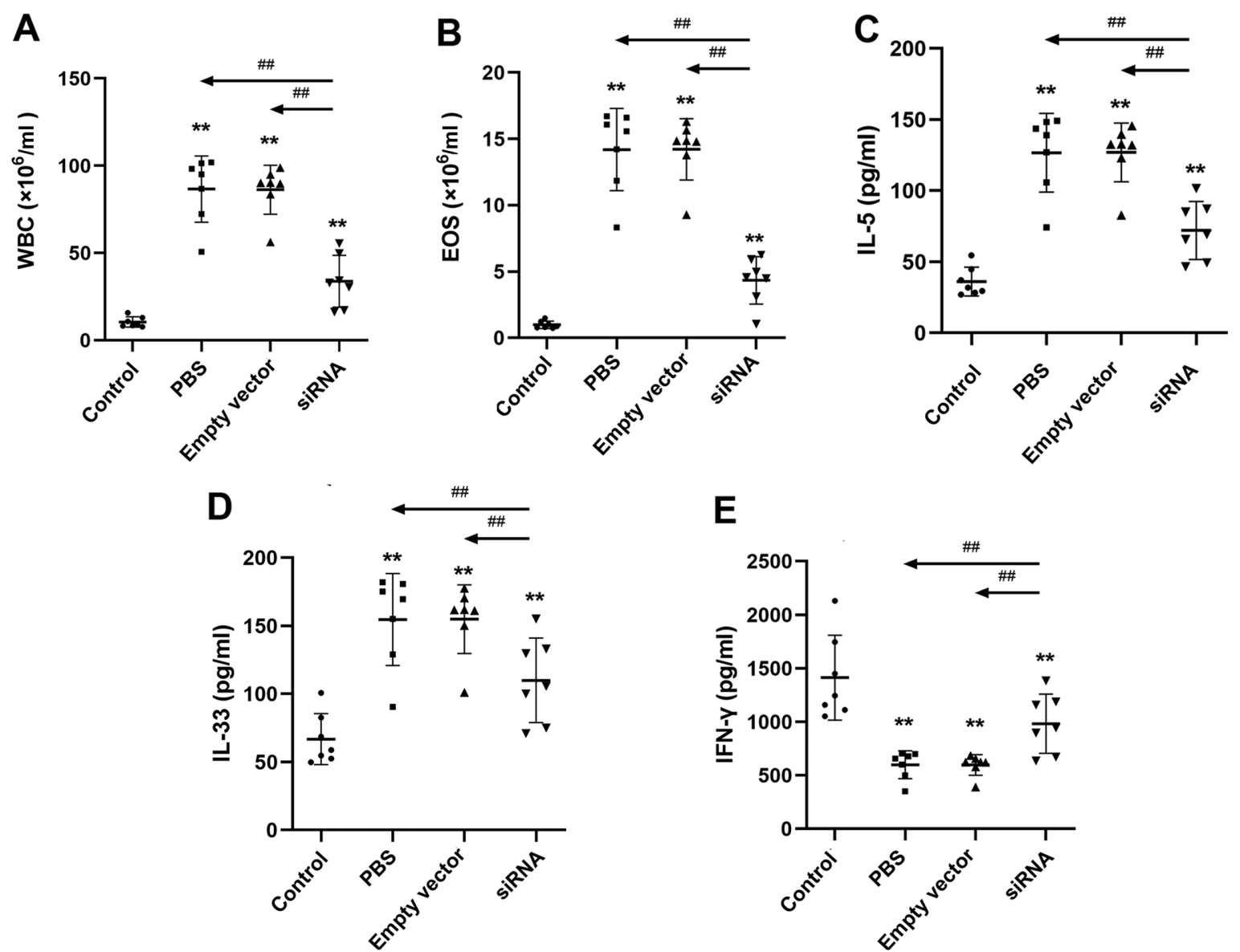

Figure 4. Quantification of WBCs, EOSs, IL-5, IL-33 and IFN- $\gamma$ in the bronchoalveolar lavage fluid of rats from four different groups. Quantification of (A) WBCs and (B) EOSs in each group. ELISA results showing the levels of (C) IL-5, (D) IL-33 and (E) IFN- $\gamma$ in each group. ${ }^{* * *} \mathrm{P}<0.01$ vs. the control group; ${ }^{\#} \mathrm{P}<0.01$ vs. the siRNA group. WBCs, white blood cells; EOSs, eosinophils; siRNA, small interfering RNA.

A

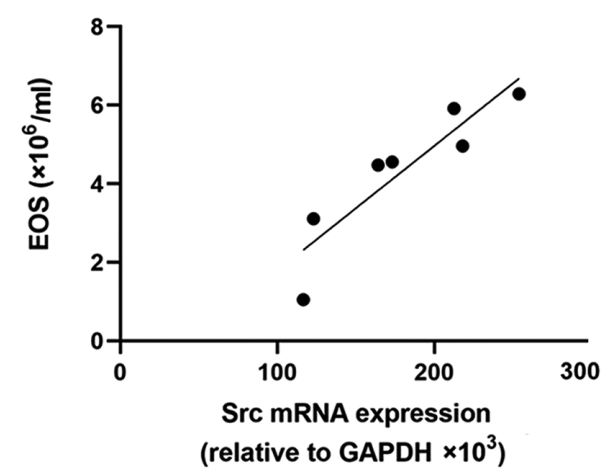

C

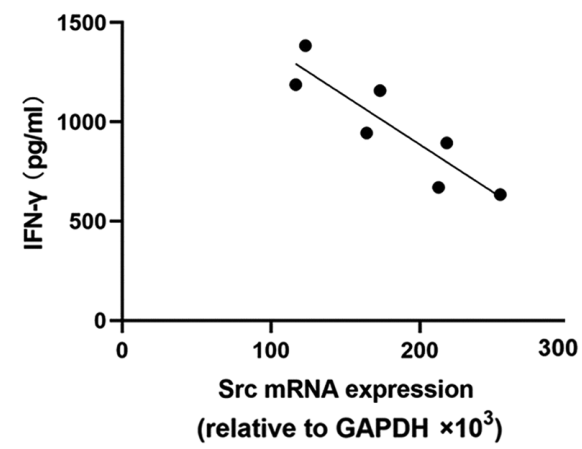

B

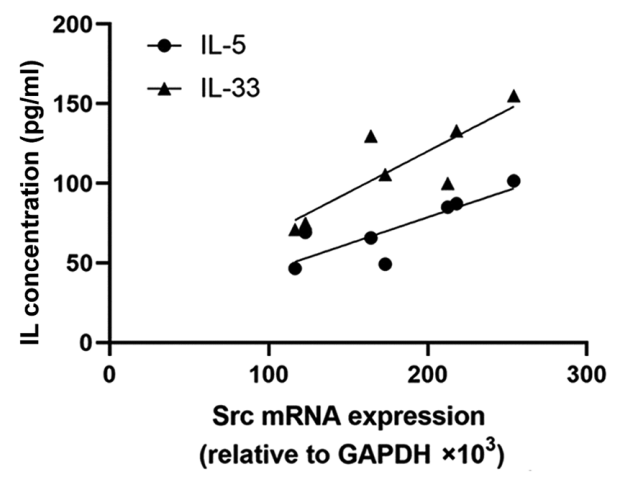

D

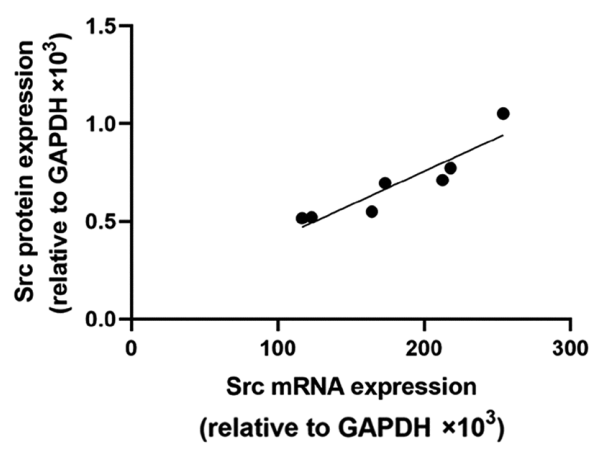

Figure 5. Correlation analysis of EOSs, IL-5, IL-33, IFN- $\gamma$ and Src protein with Src mRNA in asthma model rats treated with Src small interfering RNA. Correlation of Src mRNA expression with (A) EOSs, (B) IL-5, IL-33, (C) IFN- $\gamma$ and (D) Src protein. EOSs, eosinophils; siRNA, small interfering RNA. 


\section{Discussion}

Bronchial asthma causes airway obstruction and chronic inflammation and is one of the most common chronic diseases in developed countries (15). In 2016, the Global Burden of Disease collaboration estimated that 420,000 individuals worldwide died from asthma, which is $>1,000$ per day (1). It has been reported that $20 \%$ of patients exhibit worsening symptoms and $10 \%$ lack an effective method of control (16). When asthma reaches an advanced level, the quality of life of the patient declines. At present, commonly used methods to control asthma are progressive treatments, with strategies differing according to the severity of the disease. Glucocorticoids, leukotriene modifiers, $\beta 2$-agonists and anti-IgE therapy serve as frequently used treatment methods for asthma; however, effective targeted drugs are lacking $(17,18)$. Therefore, new technologies and therapies for asthma are popular topics of research worldwide.

Cell proliferation in airway smooth muscle (ASM) is a key contributor to chronic asthma. According to previous research, Src proteins can promote the generation and metastasis of ASM cells (19). Therefore, these molecules are potential targets in the treatment of asthma. siRNA is a double-stranded RNA that typically comprises 19-29 nucleotides in length (20). When siRNA enters target cells, it induces the degradation of mRNA and thereby inhibits gene expression $(21,22)$. Therefore, the use of siRNA technology is a powerful strategy for studying the function of genes in vitro. Xie et al (23) designed a novel pulmonary delivery system for siRNA, comprising transferrin-polyethylenimine (Tf-PEI) for the selective delivery of siRNA to activated T cells (ATCs) in the lung. Their results demonstrated that Tf-PEI polyplexes efficiently and selectively deliver siRNA to ATCs. In another study, in which dexamethasone-conjugated polyethylenimine (DEXA-PEI) was combined with anti-vitamin D binding protein (VDBP) treatment, DEXA-PEI served as an siRNA carrier molecule for the delivery of VDBP siRNA. Treatment with DEXA-PEI/VDBP siRNA effectively reduced airway inflammation, goblet cell hyperplasia and the expression of inflammatory factors such as IL-4, IL-13 and eotaxin-1 (24). The use of RNAi technology has become a standard method for silencing target genes in vitro. Due to its small size, ability to easy pass through the cell membrane and high resistance to nuclease degradation, siRNA has become the most popular tool for gene silencing (20). In the present study, RT-qPCR was employed to select the most effective siRNA for targeting the Src gene in rats.

The SD rats in the present study developed asthma following the administration of OVA. H\&E staining revealed that the rats that were exposed to OVA and treated with PBS or empty vector had lung tissue damage, inflammatory cell effusion, increased mucus secretion and narrowed alveolar intervals. These findings indicated that the asthmatic models were successfully established. siRNA targeting Src was injected intravenously into the rats in the siRNA group, and OVA and aluminium hydroxide were further administered to the rats in the PBS, empty vector and siRNA groups. The results of $H \& E$ staining in the siRNA group showed that inflammatory cell effusion and mucous secretion were markedly decreased compared with those in the PBS and empty vector groups. The levels of EOSs and WBCs in the BALF of all OVA-exposed rats were higher than those in the control group, but the levels in the siRNA group were lower than those in the PBS and empty vector groups, and no difference was detected between the PBS and empty vector groups. These results indicate that interfering with Src expression ameliorated the pathological conditions of asthma to a certain extent.

RT-qPCR and western blot analyses were performed, which indicated that the expression of Src mRNA and protein in the lung tissues of the asthmatic rats in the PBS and empty vector groups were significantly higher than those in the control group, indicating that Src was activated in the rat model of asthma. The Src mRNA and protein expression levels in the siRNA group were lower than those in the PBS and empty vector group, although higher than those in the control group. Furthermore, Src protein expression significantly positively correlated with Src mRNA expression in the siRNA group, indicating that the siRNA transfection reduced the expression of Src mRNA and suppressed the expression of Src protein in asthmatic rats, although the effect was limited.

EOSs play a key role in several chronic airway diseases, including asthma, as they promote the immune response of the airway to foreign substances, maintain a partial immune response and release granule proteins that cause tissue damage (25-27). IL-5 is an important pro-inflammatory cytokine and inhibitor of eosinophil apoptosis. Previous research has indicated that IL-5 inhibitors can effectively reduce the concentration of EOSs in the airways and blood (28). IL-33 is an activator in type 2 inflammation. IL-33 and type 2 cytokines are induced by rhinovirus in asthmatic airways and their expression levels are associated with the severity of asthma; previous studies have shown that IL-33 is an important mechanistic link in the association between rhinovirus infection and aggravation of asthma (29,30). Immune responses induced by IFN- $\gamma$ are also dominant in severe asthma in adults $(31,32)$. IFN- $\gamma$ has a regulatory effect on immune and non-immune cells and the ability to regulate mast cells in asthma. IFN- $\gamma$ has been shown to induce airway epithelial cells to release prostaglandins and stimulate $\beta$ adrenergic receptors on airway smooth muscle, thereby regulating airway function (33). In the present study, following the use of siRNA transfection technology to interfere with Src expression in rats, the concentrations of IL-5, IL-33, and IFN- $\gamma$ in the BALF were detected using ELISAs. The expression levels of IL-5 and IL-33 in the PBS and empty vector groups were higher than those in the control group. However, the administration of Src siRNA reduced the expression levels of IL-5 and IL-33 compared with those in the PBS and empty vector groups, indicating that the interference with Src expression inhibited the release of tracheal inflammatory factors. The IFN- $\gamma$ level in the siRNA group was higher than those in the PBS and empty vector groups but lower than that in the control group. These findings suggest that the expression of Src mRNA inhibits IFN- $\gamma$, leading to destruction of the tracheal structure, and this was attenuated by the knockdown of Src.

Through the correlation analysis of Src mRNA expression with EOSs, IL-5, IL-33 and IFN- $\gamma$, the levels of EOSs, IL-5 and IL-33 were shown to be positively correlated with Src mRNA expression, while IFN- $\gamma$ was negatively correlated with Src mRNA expression. However, as the sample size was small, the 
accuracy of the correlation analysis may be limited. Therefore, the results require validation by a study with a larger sample size.

In conclusion, the present study utilized gene transfer techniques to interfere with the expression of Src in rats and indicated that siRNA transfection decreased the levels of IL-5 and IL-33 and increased the levels of IFN- $\gamma$ in lung tissue, reduced the levels of WBCs and EOSs in the BALF, and effectively ameliorated tracheal tissue pathology in asthmatic rats. These results suggest that Src protein tyrosine kinase inhibitors have potential as a novel method for the treatment of asthma in the future.

\section{Acknowledgements}

Not applicable.

\section{Funding}

This research was supported by a grant from the Natural Science Foundation of Inner Mongolia of China (grant no. 2013MS1169).

\section{Availability of data and materials}

The datasets used and/or analyzed during the current study are available from the corresponding author on reasonable request.

\section{Authors' contributions}

XX and RW conceived the study, contributed to the interpretation of the results and edited the manuscript. All authors participated in the design of the study. MW and JY contributed to study design, the development of methods, specific experiments and drafting the article. TL, PX and BB performed experiments and collected data. TL performed the statistical analysis and interpretation of the results. All authors have read and approved the final manuscript. XX and RW confirm the authenticity of all the raw data. XX and RW are guarantors of this study, had full access to all the data in the study and take responsibility for the integrity of the data and the accuracy of the data analysis.

\section{Ethics approval and consent to participate}

All procedures involving animals and their care were conducted in accordance with the Guide for the Care and Use of Laboratory Animals, established by the National Academy of Sciences and published by the National Institutes of Health. The study was approved by the Ethics Committee of The Third Affiliated Hospital of Inner Mongolia Medical University (Baotou, China).

\section{Patient consent for publication}

Not applicable.

\section{Competing interests}

The authors declare that they have no competing interests.

\section{References}

1. Global Asthma Network. Global asthma report 2018. http://www. globalasthmanetwork.org. Accessed October 14, 2020.

2. British Thoracic Society; Scottish Intercollegiate Guidelines Network: British guideline on the management of asthma. Thorax 58 (Suppl 1): i1-i94, 2003.

3. Turner S, Paton J, Higgins B and Douglas G; British Guidelines on the Management of Asthma: British guidelines on the management of asthma: what's new for 2011? Thorax 66: 1104-1105, 2011.

4. Kang JY, Kim JW, Kim JS, Kim SJ, Lee SH, Kwon SS, Kim YK, Moon HS, Song JS, Park SH and Lee SY: Inhibitory effects of anti-immunoglobulin $\mathrm{E}$ antibodies on airway remodeling in a murine model of chronic asthma. J Asthma 47: 374-380, 2010.

5. Deng YM, Xie QM, Tang HF, Sun JG, Deng JF, Chen JQ and Yang SY: Effects of ciclamilast, a new PDE 4 PDE4 inhibitor, on airway hyperresponsiveness, PDE4D expression and airway inflammation in a murine model of asthma. Eur J Pharmacol 547: 125-135, 2006.

6. Sun JG, Deng YM, Wu X, Tang HF, Deng JF, Chen JQ, Yang SY and Xie QM: Inhibition of phosphodiesterase activity, airway inflammation and hyperresponsiveness by PDE4 inhibitor and glucocorticoid in a murine model of allergic asthma. Life Sci 79: 2077-2085, 2006.

7. Charbe NB, Amnerkar ND, Ramesh B, Tambuwala MM, Bakshi HA, Aljabali AAA, Khadse SC, Satheeshkumar R, Satija S, Metha M, et al: Small interfering RNA for cancer treatment: Overcoming hurdles in delivery. Acta Pharm Sin B 10: 2075-2109, 2020.

8. Corren J: Cytokine inhibition in severe asthma: Current knowledge and future directions. Curr Opin Pulm Med 17: 29-33, 2011.

9. Barnes PJ: Cytokine-directed therapies for the treatment of chronic airway diseases. Cytokine Growth Factor Rev 14: 511-522, 2003.

10. Holgate ST: Cytokine and anti-cytokine therapy for the treatment of asthma and allergic disease. Cytokine 28: 152-157, 2004.

11. Walsh GM: Targeting eosinophils in asthma: Current and future state of cytokine- and chemokine-directed monoclonal therapy. Expert Rev Clin Immunol 6: 701-704, 2010.

12. Strasner AB, Natarajan M, Doman T, Key D, August A and Henderson AJ: The Src kinase Lck facilitates assembly of HIV-1 at the plasma membrane. J Immunol 181: 3706-3713, 2008.

13. NCBI: Rattus norvegicus SRC proto-oncogene, non-receptor tyrosine kinase (Src), mRNA. NCBI Reference Sequence NM_031977.1. https://www.ncbi.nlm.nih.gov/nuccore/14010834/. Accessed June 5, 2018.

14. Livak KJ and Schmittgen TD: Analysis of relative gene expression data using real-time quantitative PCR and the 2(-Delta Delta C(T)) method. Methods 25: 402-408, 2001.

15. Lee JU, Kim JD and Park CS: Gene-environment interactions in asthma: Genetic and epigenetic effects. Yonsei Med J 56: 877-886, 2015.

16. Gallelli L, Busceti MT, Vatrella A, Maselli R and Pelaia G: Update on anticytokine treatment for asthma. Biomed Res Int 2013: 104315, 2013.

17. Guo S and Kemphues KJ: par-1, a gene required for establishing polarity in C. elegans embryos, encodes a putative Ser/Thr kinase that is asymmetrically distributed. Cell 81: 611-620, 1995.

18. Fire A, Xu S, Montgomery MK, Kostas SA, Driver SE and Mello CC: Potent and specific genetic interference by double-stranded RNA in caenorhabditis elegans. Nature 391: 806-811, 1998.

19. Krymskaya VP, Goncharova EA, Ammit AJ, Lim PN, Goncharov DA, Eszterhas A and Panettieri RA Jr: Src is necessary and sufficient for human airway smooth muscle cell proliferation and migration. FASEB J 19: 428-430, 2005.

20. O'Keefe EP: siRNAs and shRNAs: Tools for protein knockdown by gene silencing. Mater Methods 3: 197, 2013.

21. McManus MT and Sharp PA: Gene silencing in mammals by small interfering RNAs. Nat Rev Genet 3: 737-747, 2002.

22. McManus MT, Haines BB, Dillon CP, Whitehurst CE, van Parijs L, Chen J and Sharp PA: Small interfering RNA-mediated gene silencing in T lymphocytes. J Immunol 169: 5754-5760, 2002.

23. Xie Y, Kim NH, Nadithe V, Schalk D, Thakur A, Kılıç A, Lum LG, Bassett DJP and Merkel OM: Targeted delivery of siRNA to activated T cells via transferrin-polyethylenimine (Tf-PEI) as a potential therapy of asthma. J Control Release 229: 120-129, 2016.

24. Choi M, Gu J, Lee M and Rhim T: A new combination therapy for asthma using dual-function dexamethasone-conjugated polyethylenimine and vitamin D binding protein siRNA. Gene Ther 24: 727-734, 2017. 
25. Leo C and Chen JD: The SRC family of nuclear receptor coactivators. Gene 245: 1-11, 2000.

26. Liao L, Kuang SQ, Yuan Y, Gonzalez SM, O'Malley BW and $\mathrm{Xu} \mathrm{J}$ : Molecular structure and biological function of the cancer-amplified nuclear receptor coactivator SRC-3/AIB1. J Steroid Biochem Mol Biol 83: 3-14, 2002.

27. Xu J, Qiu Y, DeMayo FJ, Tsai SY, Tsai MJ and O'Malley BW: Partial hormone resistance in mice with disruption of the steroid receptor coactivator-1 (SRC-1) gene. Science 279: 1922-1925, 1998.

28. Karelina T, Voronova V, Demin O, Colice G and Agoram BM: A mathematical modeling approach to understanding the effect of anti-interleukin therapy on eosinophils. CPT Pharmacometrics Syst Pharmacol 5: 608-616, 2016.

29. Jackson DJ, Makrinioti H, Rana BM, Shamji BW, Trujillo-Torralbo MB, Footitt J, Del-Rosario J, Telcian AG, Nikonova A, Zhu J, et al: IL-33-dependent type 2 inflammation during rhinovirus-induced asthma exacerbations in vivo. Am J Respir Crit Care Med 190: 1373-1382, 2014.
30. Barlow JL, Peel S, Fox J, Panova V, Hardman CS, Camelo A, Bucks C, Wu X, Kane CM, Neill DR, et al: IL-33 is more potent than IL-25 in provoking IL-13-producing nuocytes (type 2 innate lymphoid cells) and airway contraction. J Allergy Clin Immunol 132: 933-941, 2013.

31. Raundhal M, Morse C, Khare A, Oriss TB, Milosevic J, Trudeau J, Huff R, Pilewski J, Holguin F, Kolls J, et al: High IFN- $\gamma$ and low SLPI mark severe asthma in mice and humans. J Clin Invest 125: 3037-3050, 2015.

32. Leavy O: Asthma and allergy: An IFN $\gamma$ bias in severe asthma. Nat Rev Immunol 15: 466-467, 2015.

33. Kawakami T and Galli SJ: Regulation of mast-cell and basophil function and survival by IgE. Nat Rev Immunol 2: 773-786, 2002.

(i) (9) This work is licensed under a Creative Commons Attribution-NonCommercial-NoDerivatives 4.0 International (CC BY-NC-ND 4.0) License. 